\title{
A fundação do curso de Serviço Social em universidades públicas federais no Rio Grande do Sul: contradições, possibilidades e desafios ao desenvolvimento local-regional
}

\author{
The foundation of the Social Work course in federal public universities in Rio \\ Grande do Sul: contradictions, possibilities and challenges to local-regional \\ development
}

\section{La fundación del curso de Trabajo Social en universidades públicas federales en Rio Grande do Sul: contradicciones, posibilidades y desafíos para el desarrollo local-regional}

\author{
Cristina Kologeski Fraga ${ }^{1}$ \\ Fábio Jardel Gaviraghi ${ }^{1}$ \\ Cristina Pinto Albuquerque ${ }^{2}$ \\ Clara Cruz Santos ${ }^{2}$
}

\begin{abstract}
Recebido em 07/01/2020; revisado e aprovado em 07/05/2020; aceito em 26/05/2020.
DOI: http://dx.doi.org/10.20435/inter.v21i3.2883
\end{abstract}

\begin{abstract}
Resumo: Este artigo intenciona refletir sobre a criação dos primeiros cursos de graduação em Serviço Social nas universidades federais gaúchas do interior do Rio Grande do Sul, mais especificamente na Universidade Federal do Pampa (Unipampa/Campus São Borja), primeiro curso público, federal e gratuito no interior do estado gaúcho na área de Serviço Social, e na Universidade Federal de Santa Maria (UFSM), terceiro curso fundado. O artigo também aborda as possibilidades da expansão dos cursos superiores em Serviço Social nas universidades gaúchas, no que tange ao desenvolvimento local-regional, trazendo, além disso, suas contradições e desafios ao modo como tais cursos foram sendo implantados.
\end{abstract}

Palavras-chave: Serviço Social; assistente social; universidade pública; Reuni.

Abstract: This article intends to reflect on the creation of the first undergraduate courses in Social Work at the gaucho federal universities in the interior of Rio Grande do Sul, more specifically at the Federal University of Pampa (Unipampa/São Borja Campus), the first public, federal and free course in the interior of the state of Rio Grande do Sul in the area of Social Work, and at the Federal University of Santa Maria (UFSM), third funded course. The article also discusses the possibilities of the expansion of higher education courses in Social Work in the state of Rio Grande do Sul, concerning local-regional development, bringing, furthermore, its contradictions and challenges to the way such courses were being implemented.

Keywords: Social Work; social worker; public university; Reuni.

Resumen: Este artículo tiene la intención de reflexionar acerca de la creación de los primeros cursos de graduación en Trabajo Social en las universidades federales del interior de Rio Grande do Sul, más específicamente en la Universidad Federal del Pampa (Unipampa/Campus São Borja), el primer curso público, federal y gratuito en el interior del estado de Rio Grande do Sul en el área de Trabajo Social, y en la Universidad Federal de Santa María (UFSM), tercer curso creado. El artículo también analiza las posibilidades de expansión de los cursos superiores en Trabajo Social en las universidades de Rio Grande do Sul, en lo que concierne al desarrollo local-regional, presentando, además, sus contradicciones y desafíos a la forma con que se implementaron tales cursos.

Palabras clave: Trabajo Social; asistente social; universidad pública; Reuni.

\footnotetext{
${ }^{1}$ Universidade Federal de Santa Maria (UFSM), Santa Maria, Rio Grande do Sul, Brasil.

${ }^{2}$ Universidade de Coimbra, Coimbra, Portugal.
} 


\section{INTRODUÇÃO}

Abordar a criação dos cursos de graduação em Serviço Social em universidades públicas federais no interior do Rio Grande do Sul é, antes de tudo, um compromisso para quem teve a oportunidade de protagonizar esse processo histórico do Serviço Social gaúcho. Isso porque o Serviço Social brasileiro já tem mais de 80 anos e, nesse percurso, alcançou sua maioridade, perpassando crises, autocríticas e, também, amadurecimento e conquistas no campo de sua atuação profissional. Particularmente, no estado gaúcho, a formação profissional em Serviço Social veio sempre marcada por instituições privadas de ensino superior.

Exatamente por isso faz-se necessário resgatar o significado e a importância, para o desenvolvimento local-regional, da expansão dos cursos de graduação de Serviço Social em solo gaúcho interiorano em universidades públicas e federais, sem, evidentemente, deixar de trazer à tona suas contradições e desafios. Isso exige uma breve retrospectiva dessas oito décadas do Serviço Social nacional, de sua gênese como profissão. Sendo assim, essa retomada abrange aspectos históricos considerados relevantes no que tange à origem e profissionalização do Serviço Social no Brasil, bem como do Serviço Social no Rio Grande do Sul, e ao movimento de reconceituação. Aponta, ainda, alguns desafios e perspectivas à profissão de assistente social no cenário atual.

Conforme evoca Villar (2015), os cursos de graduação em Serviço Social no Rio Grande do Sul estiveram concentrados, por sessenta e um anos, exclusivamente no setor privado. No século XXI, essa supremacia foi desfeita quando, em 2006, foi criado o primeiro curso público no estado e, nos quatro anos seguintes, mais dois cursos.

Em termos de estrutura, este artigo está constituído, inicialmente, por esta introdução, para, na seção seguinte, serem abordados aspectos da historicidade do Serviço Social brasileiro em seu processo octogenário. Em um segundo momento, é feita uma reflexão sobre a criação dos cursos de Serviço Social no estado gaúcho. Destaca-se a constituição da primeira escola de Serviço Social pública no Rio Grande do Sul - devido à implantação da proposta de expansão do ensino superior público no Brasil -, a Unipampa, localizada no município de São Borja, e o curso advindo do programa de Reestruturação e Expansão das Universidades Federais (Reuni) na Universidade Federal de Santa Maria (UFSM). Por fim, nas considerações finais, são tecidos comentários crítico-reflexivos acerca do processo de expansão dos cursos de Serviço Social.

\section{O SERVIÇO SOCIAL BRASILEIRO: BREVE RETROSPECTIVA}

Ao buscar as origens do Serviço Social, percebe-se que esse curso tem sua gênese em países da Europa e dos Estados Unidos, no final do século XIX, no contexto de desenvolvimento do capitalismo. Bulla (2000) explica que, nessa época, a alienação do trabalhador e a exploração do trabalho pelo capital propiciaram a acumulação e a expansão da era industrial, agudizando-se a questão social. Para enfrentar a questão social e suas refrações, entendeu-se, na época, que a solução estava na reforma social. Assim, a Igreja Católica tornou-se partidária da intervenção do Estado e a Encíclica Rerum Novarum é um marco, recomendando a promulgação de leis trabalhistas e a adoção de medidas em benefícios da classe trabalhadora.

Nesse diapasão, Bulla (2000) ainda destaca que o Serviço Social, como profissão, é oriundo de grupos de orientação cristã, católica ou protestante, partidários da reforma social. Embora existissem, em períodos anteriores, diferentes formas de ajuda e já se iniciasse, desde o fim da 
época moderna, a organização da assistência, a institucionalização da profissão só ocorreu nos marcos do desenvolvimento capitalista, resultantes da divisão social do trabalho e do acirramento da questão social ${ }^{3}$, emergindo como uma das maneiras de correção da disfunção do sistema capitalista.

Para que o Serviço Social se afirmasse como profissão e tivesse o reconhecimento social, foram requeridas a elaboração de um corpo de conhecimentos próprios e a formação de profissionais que respondessem a contento as demandas sociais vigentes, para que fosse possível uma contribuição significativa à sociedade. Com esse objetivo é que foram organizados os cursos de Serviço Social (BULLA, 2000).

Data de 1898 a criação do primeiro curso de Serviço Social, em Nova lorque, pela Sociedade de Organização de Caridade, tendo a contribuição da pioneira Mary Richmond: "[...] que, com suas pesquisas e obras, lançou as bases paradigmáticas do Serviço Social, às quais foram sendo acrescidas novas contribuições teórico-metodológicas ao longo deste século" (BULLA, 2000, p. 163).

No Brasil, o Serviço Social emerge na década de 30 do século passado com inspiração franco-belga (neotomismo), fruto de um movimento da burguesia com o apoio da Igreja Católica, mais precisamente em 1932, com a criação do Centro de Estudos e Ação Social de São Paulo (Ceas), tendo por finalidade promover a formação de seus membros pelo estudo da doutrina social da Igreja (DALLA NORA, 2002). Em 1936, é fundada a primeira escola de Serviço Social do Brasil em São Paulo, que mais tarde viria se tornar a Pontifícia Universidade Católica de São Paulo (PUC-SP). Em 1937, em meio ao Golpe do Estado Novo, foi criado o curso de Serviço Social no Rio de Janeiro, posteriormente vinculado à Pontifícia Universidade Católica (PUC-Rio). Em 1945, cria-se a primeira escola de Serviço Social no Rio Grande do Sul, mais especificamente em Porto Alegre, denominada posteriormente como Faculdade de Serviço Social da Pontifícia Universidade Católica (PUCRS). Posteriormente, outras escolas vão sendo criadas em diversos lugares do Brasil, todas com formação de práticas sociais de feições burguesas, prontas para responderem às exigências do sistema capitalista.

A extensão dos cursos de formação de assistentes sociais foi possível à medida que os profissionais passaram a adotar um papel ideológico de controle social, garantindo, em última instância, uma situação favorável à autocracia burguesa. Conforme elucida Bulla (2000), diferentemente da Alemanha e de outros países da Europa, o curso de Serviço Social é, em todo o Brasil, reconhecido como de nível universitário.

Outro marco importante para o Serviço Social brasileiro é sua regulamentação como profissão. Embora tenha sido criado nos anos trinta do século passado, somente em 1953 é publicada a Lei 1.889, que dispõe sobre a primeira regulamentação do Serviço Social como profissão.

No contexto brasileiro, vários cursos de Serviço Social se situam em universidades públicas, porém a maioria agrega-se a universidades privadas. No caso do Rio Grande do Sul, essa situação é ainda mais evidente, pois somente após 61 anos de história do Serviço Social no Estado, mais precisamente no fim de 2006, é inaugurado o primeiro Curso de Serviço Social público e gratuito.

\footnotetext{
${ }^{3}$ Questão social que pode ser compreendida como o conflito suscitado entre a compra (detentores dos meios de produção) e a venda da força de trabalho (trabalhadores), que gera manifestações. Essas manifestações, por sua vez, são subdivididas entre a geração de desigualdades (desemprego, exploração, analfabetismo, fome, pobreza, entre outros, que constituem demandas de trabalho dos assistentes sociais) e de rebeldia e resistência (todas as formas de rebeldia vivenciadas pelos sujeitos para resistir às desigualdades, como conselhos, sindicatos, políticas, programas e projetos sociais, associações etc.).
} 
Fato memorável, tendo em vista os contornos burgueses assumidos pela profissão desde as suas origens.

Aguiar (1982), ao citar as fases do Serviço Social no Brasil em termos de data, destaca que: as duas primeiras fases ocorreram no período de 1945 a 1955. A terceira fase aconteceu entre 1956 e 1964, mais precisamente no fim da década de 50 até 64. Em 1964, houve a ruptura da mobilização popular, com o golpe militar. A quarta fase ocorreu após 1964 e, com mais ênfase, a partir de 1968 (AGUIAR, 1982).

Na década de 1940, no Brasil, o Estado assume a dianteira como empregador dos(as) assistentes sociais, reiterando uma ótica paternalista e conservadora de controle social. Nos anos de 1950, no auge do governo JK, o contexto do capitalismo democrático internacionalmente dependente e atrelado ao Estado impulsiona investimentos de infraestrutura na ótica do desenvolvimentismo, trazendo para o país o método de intervenção de desenvolvimento de comunidade, convocando os profissionais a assumirem: "a articulação da harmonia social na relação Estado/Sociedade". O método de organização de comunidade consistia num esforço comunitário para "trabalhar o meio social, as condições imediatas" (FALEIROS, 1997, p. 15).

Em meados da década de 60 do século passado, grupos de assistentes sociais passam a questionar o Serviço Social quanto a sua natureza e operacionalidade. Segundo autores como Aguiar (1982), a reconceituação nasceu, inicialmente, do desejo de superar o Serviço Social tradicional, que foi transplantado da Europa e dos EUA. Nesse período, os assistentes sociais pretendiam desenvolver uma instrumentalidade que fosse direcionada por uma intencionalidade que viesse ao encontro da realidade brasileira e latino-americana (continente subdesenvolvido e dependente). Portanto, nesse primeiro momento do movimento de reconceituação, não se questionaram as estruturas da realidade brasileira e latino-americana, pois continuou se respaldando no referencial teórico funcionalista/positivista. Apenas posteriormente que emergiram posturas durante este movimento que foram condizentes com a perspectiva crítica e dialética ${ }^{4}$.

Netto (2005, p. 12) destaca que a principal conquista da Reconceituação se situa em um plano preciso:

[...] o da recusa do profissional de Serviço Social de situar-se como um agente técnico puramente executivo (quase sempre um executor terminal de políticas sociais). Reivindicando atividades de planejamento para além dos níveis de intervenção microssocial, valorizando nas funções profissionais o estatuto intelectual do assistente social (abrindo, pois, a via para a inserção da pesquisa como atributo também do Serviço Social), a Reconceituação assentou as bases para a requalificação profissional rechaçando a subalternidade [...].

Um balanço mais aprofundado acerca do movimento de reconceituação certamente há de resgatar muitas outras conquistas e talvez até equívocos próprios de todo movimento seminal e instaurador, delimitado no espaço temporal, por estudiosos a exemplo de Netto (2005), como uma década (1965-1975), e denominado, pelo mesmo autor, de inconcluso, dada a ditadura militar instaurada no Brasil a partir de 1964, que perdurou por mais de vinte anos. Por isso, o autor ainda salienta que é somente a partir da segunda metade dos anos setenta, quando a ditadura começa a dar sinais de esgotamento, que começam as ressonâncias das tendências

\footnotetext{
${ }^{4}$ Aguiar (1982) destaca também que, a partir de 1960, passa a ocorrer uma ruptura por parte daqueles ("geração 65") que começam a assumir uma postura na visão dialética, inclusive na sua versão materialista. É a partir da década de 60 que se instaura o movimento de reconceituação do Serviço Social.
} 
que na Reconceituação apontavam para uma crítica radical ao tradicionalismo. Nos anos 1980, - Serviço Social brasileiro começa a despertar para uma perspectiva crítica, tanto teórica quanto prática, que se constituiu a partir da Reconceituação.

Nessa perspectiva, lamamoto (2014a) destaca que a década de 80 do século passado foi extremamente fértil na definição de rumos técnico-acadêmicos e políticos para o Serviço Social brasileiro. Hoje existe um projeto profissional, e este encontra suas diretrizes norteadoras desdobradas no Código de Ética Profissional do Assistente Social, na Lei de Regulamentação da Profissão de Assistente Social e também nas Diretrizes Curriculares do Curso de Serviço Social. A autora ressalta ainda que a Associação Brasileira de Ensino e Pesquisa em Serviço Social (Abepss), na formulação de sua proposta de currículo mínimo, reconhece ser a investigação e a capacitação continuada dos profissionais e professores requisitos indispensáveis para a qualificação de assistentes sociais conciliados com os novos tempos.

As diretrizes curriculares contêm dois elementos que representam uma ruptura com a concepção predominante nos anos 1980: "O primeiro é considerar a questão social como base de fundação sócio-histórica do Serviço Social e o segundo é apreender a 'prática profissional' como trabalho e o exercício profissional inscrito em um processo de trabalho" (IAMAMOTO, 2014a, p. 57).

Nesse sentido, Faleiros (2004) evidencia que o Código de Ética do(a) Assistente Social e a Lei de Regulamentação da profissão, ambos de 1993, destacam-se como meios essenciais para se consolidar uma perspectiva de transformação social e um projeto ético-político da profissão que tem profundas raízes no movimento de reconceituação do Serviço Social.

O Código de Ética do(a) assistente social versa sobre uma dimensão fundamental da ética profissional de caráter normativo e jurídico que regulamenta a profissão de assistente social no que concerne às implicações éticas de sua ação. Sugere o dever ser profissional, na medida em que estabelece normas, direitos, deveres e proibições.

Entre os princípios fundamentais do Código de Ética do(a) Assistente Social (AS) (CONSELHO FEDERAL DE SERVIÇO SOCIAL [CFESS], 1993), destacam-se:

[...] o reconhecimento da liberdade como valor ético central e das demandas políticas a elas inerentes - autonomia, emancipação e plena expansão dos indivíduos sociais; defesa intransigente dos Direitos Humanos e recusa do arbítrio e do autoritarismo; ampliação e consolidação da cidadania [...]; defesa do aprofundamento da democracia, enquanto socialização da participação política e da riqueza socialmente produzida; posicionamento em favor da equidade e da justiça social [...]; empenho na eliminação de todas as formas de preconceito, incentivando o respeito à diversidade, à participação de grupos socialmente discriminados e à discussão das diferenças; garantia do pluralismo, através do respeito às correntes profissionais democráticas existentes e suas expressões teóricas, e compromisso com o constante aprimoramento intelectual; opção por um projeto profissional vinculado ao processo de construção de uma nova ordem societária, sem dominação-exploração de classe, etnia e gênero; articulação com os movimentos de outras categorias que partilhem dos princípios deste Código [...] Compromisso com a qualidade dos serviços prestados à população e com o aprimoramento intelectual, na perspectiva de competência profissional e exercício do SS sem ser discriminado, nem discriminar, por questões de inserção, por questões de inserção de classe social, gênero, etnia, religião, nacionalidade, orientação sexual, idade e condição física.

Portanto é em um cenário adverso, permeado de limitações e percalços, em que se visualizam desafios e perspectivas de concretização dos princípios fundamentais do Código de 
Ética dos profissionais de Serviço Social, que não apenas emoldura, mas molda novas condições de trabalho do Assistente Social, redimensionando a profissão. O ponto de partida da análise, conforme lamamoto (2014a), são as várias mudanças que vêm afetando o mundo da produção, na esfera do Estado e das políticas públicas.

Faz-se necessário que o profissional de Serviço Social consiga analisar como tais mudanças vêm estabelecendo novas mediações nas expressões da questão social hoje, nas demandas da profissão e nas respostas desse profissional. lamamoto (2014a) parte da premissa de que o contexto sócio-histórico não se reduz a um pano de fundo para que se possa, depois, discutir o trabalho profissional. Ele atravessa e conforma o cotidiano do exercício profissional do(a) assistente social, afetando as suas condições e as relações de trabalho, assim como as condições de vida da população usuária, sendo necessário a esses(as) profissionais, em primeiro lugar, muito estudo, busca constante para atuarem com persistência, criatividade e articulação com as diversas áreas do saber.

Sendo assim, as pesquisas em Serviço Social - e seu respectivo tema e objeto - necessitam estar atreladas a situações concretas da realidade social e ter aproximação com as intervenções realizadas pelos assistentes sociais, mais especificamente na universidade, por meio da extensão comunitária. Assim, podem ter uma utilidade social mais imediata, não implicando apenas o conhecimento realizado com a finalidade descritiva e contemplativa. Para que os estudos e as pesquisas tenham utilidade social, é fundamental estarem alicerçados no conjunto de conhecimentos, habilidades, atribuições, competências e compromissos necessários à realização dos processos de trabalho, em qualquer espaço ou âmbito de atuação em que o assistente social os realize.

\section{A CRIAÇÃO DOS CURSOS DE SERVIÇO SOCIAL EM UNIVERSIDADES PÚBLICAS FEDERAIS NO RIO GRANDE DO SUL: OS CASOS DA UNIPAMPA E DA UFSM}

O curso de Serviço Social da Unipampa, criado no campus de São Borja, fronteira oeste do estado do Rio Grande do Sul, é fruto do programa de expansão das Universidades Federais do Brasil e integra a Unipampa conforme o Projeto de Lei n. 7.204/2006.

A Unipampa, além da promoção da educação superior por meio do ensino, da pesquisa e da extensão, foi implantada e implementada para minimizar o processo de estagnação econômica da região, entendendo que, enquanto projeto de governo, a educação contribui na promoção do desenvolvimento local e regional, pois se buscava incorporar a região ao mapa do desenvolvimento socioeconômico do estado.

A presença de instituições de Ensino Superior em qualquer região é elemento fundamental de desenvolvimento econômico e social, bem como de melhoria da qualidade de vida da população, uma vez que proporciona o aproveitamento das potencialidades locais. Da mesma forma, os municípios que têm representações de universidades estão permanentemente desfrutando de um acentuado processo de transformação econômica e cultural, mediante parcerias firmadas entre essas instituições e as comunidades em que estão inseridas, fomentando a troca de informações e a interação científica, tecnológica e intelectual, as quais permitem o compartilhamento de conhecimentos necessários ao estabelecimento do desenvolvimento sustentável que respeite e estimule os sistemas produtivos locais, além do fortalecimento das instâncias de educação popular. 
A educação superior brasileira, segundo a Lei de Diretrizes e Bases (LDB), Lei n. 9.394, em seu artigo 43, item IV, visa "estimular o conhecimento dos problemas do mundo presente, em particular os nacionais e regionais, prestar serviços especializados à comunidade e estabelecer com esta uma relação de reciprocidade" (BRASIL, 1996). Esses elementos, norteadores da atuação das Instituições de Ensino Superior (IES), vêm estimulando inúmeros pesquisadores e teóricos a discutir e pensar o papel da universidade, buscando compreender seu conceito, seus objetivos e sua missão.

Chauí (2003, p. 5) entende a universidade como uma instituição social e, como tal, esta "exprime de maneira determinada a estrutura e o modo de funcionamento da sociedade como um todo", pois, em seu interior, existem atitudes, opiniões e projetos conflitantes, "que exprimem divisões e contradições da sociedade". Frantz (2013, p. 18-23) também declara que a universidade "é um produto da ação e da reflexão humana, um espaço de poder, exercidas pelas mais diversas formas, por meio das mais diversas áreas e campos de saberes", sendo um lugar de "afirmação do diálogo, da argumentação, do debate entre os seres humanos, no campo das ideias [...] tendo por denominador comum a liberdade".

Nessa perspectiva, como apontam os autores, a universidade é entendida como um espaço de diálogo, de argumentação, de reflexão, mas não isenta de conflitos, de divergências de opiniões e de contradições que influenciam no direcionamento e na intencionalidade do conhecimento produzido, no modo de funcionamento da própria universidade e, inclusive, na intervenção na realidade. Além disso, como pontua Frantz (2013, p. 17), a universidade não pode ser neutra e precisa agir/fazer "como lugar de conhecimento em favor da vida, a questão suprema de nossa existência"; ou seja, é função básica da universidade promover a ciência e o desenvolvimento da sociedade, tendo a vida como valor ético central nas ações de ensino, pesquisa e extensão. Frantz (2010, p. 70) também destaca que a universidade "é um espaço privilegiado para cultivar a memória da humanidade, a partir do conhecimento científico da sociedade, e assim constituirse em um olhar para o futuro". Para tanto, é preciso interpretar o mundo e seus movimentos, sendo, dessa maneira, papel da universidade a produção de conhecimento que leve em conta o seu objetivo, que é a formação.

Assim sendo, a construção coletiva de formação acadêmica no Serviço Social vai no sentido explicitado por lamamoto (2014b, p 625): “[...] norteia-se pela defesa da universidade pública, gratuita e de qualidade, direcionada aos interesses da coletividade e enraizada na realidade regional e nacional; a universidade que cultiva razão crítica e o compromisso com valores universais, coerente com sua função pública [...]".

A expansão da educação pública superior, com a criação da Unipampa, além de concretizar um antigo sonho da população local, permitiu que muitos jovens permanecessem em suas regiões de origem e adquirissem qualificações necessárias para impulsionar o progresso desses espaços geográficos, na medida em que vem propiciando a formação de profissionais qualificados. Agregam-se ainda, com a aprovação do projeto de lei que selou a futura Universidade Federal do Pampa, o desejo e o empenho coletivo das comunidades das cidades em que já estão sendo desenvolvidos cursos superiores de graduação e pós-graduação, bem como das instâncias políticas que mobilizaram as Prefeituras Municipais, as Câmaras de Vereadores e os deputados estaduais e federais ligados a essa região.

Nesse sentido, é relevante a criação do curso de Serviço Social nas universidades públicas no interior do estado tanto para o atendimento dos interesses acadêmicos dessas universidades 
quanto para a população em geral, devido ao fato de ser uma região de fronteira (Brasil com a Argentina), além de outras características socioeconômicas e culturais peculiares da região. Há de se considerar a vastidão de demandas sociais urbanas e rurais nos municípios da região, como apontavam as estatísticas ${ }^{5}$ e os estudos sobre aquela realidade, em especial para a população de jovens e adultos que não tinham oportunidades de emprego e muito menos estavam preparados para gerarem renda própria.

Na Fronteira Oeste do Estado Rio Grande do Sul, região em que se localiza o Campus São Borja, vivia-se uma realidade muito contraditória e vinculada à questão social brasileira. Essa realidade é advinda da desigualdade social existente na referida região, pois existe uma grande quantidade de terra pertencente a latifundiários - famílias historicamente tradicionais na região. Sob outro enfoque, constata-se que, por ser uma região de fronteira, extremo sul do Brasil, com uma grande extensão de terras destinada ao setor primário, por meio do plantio de trigo e soja, tratava-se de uma região estagnada economicamente. Essa realidade constituía-se em um dos motivos pelo qual o município de São Borja, bem como essa região, foi contemplado pela expansão do ensino superior, por meio do Campus, pois foi ao encontro da proposta do governo federal de expansão do ensino superior público destinado também a um público advindo de classes pobres.

Foi em meio a um contexto adverso, em uma região longínqua da capital gaúcha e esquecida em termos de desenvolvimento social, que o curso de Serviço Social foi criado em 2006, na modalidade diurna e com apenas duas docentes substitutas. Em janeiro de 2007, iniciou-se o ingresso de profissionais docentes por meio do concurso público realizado pela UFSM. O início do curso foi permeado pela precarização de infraestrutura, de pessoal docente e de técnicos administrativos. Criado por meio do Programa Universidade para Todos (Prouni), o curso de Serviço Social/Campus São Borja foi instituído em um dos dez campi da Universidade Federal do Pampa. Melhor referindo, além de ser criado o curso, esse foi estabelecido em uma universidade nova, tutelada em cinco campi pela Universidade Federal de Pelotas (UFPel) e os outros cinco pela Universidade Federal de Santa Maria (UFSM); no caso do curso de Serviço Social, ele foi estabelecido em um dos campi tutelado pela UFSM.

Na atualidade, a Unipampa tem 65 cursos com alunos vinculados, conforme o gráfico a seguir.

\footnotetext{
${ }^{5}$ Considerando-se dados obtidos junto à Secretaria de Coordenação e Planejamento do Rio Grande do Sul, esse Estado tem ainda um enorme contingente de pessoas pobres. Para se ter uma noção da situação estadual e em especial das regiões do médio Uruguai e Missões, deve-se analisar os dados do Censo 2000, nos quais se observava que a distribuição da renda no Rio Grande do Sul ocorreu de modo heterogêneo, embora seja possível determinar as áreas com maior incidência de pessoas com rendimentos mais elevados. Segundo a Pesquisa Nacional por Amostra de Domicílios do IBGE, em 2005, 25,04\% das pessoas de dez anos ou mais de idade no Brasil, na época, apresentavam rendimento médio mensal de até um salário mínimo, enquanto no Rio Grande do Sul o valor era de 19,73\%. Conforme dados do IBGE de 2015, no Brasil, 39,84\% das pessoas viviam de $1 / 2$ a 1 salário mínimo, segundo o "valor do rendimento médio mensal das pessoas de 15 anos ou mais de idade, economicamente ativas na semana de referência", ao modo que, no Rio Grande do Sul, no mesmo ano, 12,80\% das pessoas viviam com 1/2 a 1 salário mínimo, segundo o mesmo referencial. Em 2015, segundo a Fundação de Economia e Estatística (FEE), o PIB per capita do Estado do RS era de R\$33.960,36 - um pouco acima da média nacional, de R\$ 29.326,33. Entretanto estudos indicaram a existência de cerca de dois milhões de pessoas em situação de pobreza vivendo no solo gaúcho. São números expressivos e preocupantes. Torna-se evidente que, para uma família obter um adequado padrão de vida, é importante que ela possa dispor de rendimentos satisfatórios. Esse propósito tem relação com os aspectos que envolvem trabalho e rendimento, portanto também é necessário investimento em formação técnica e superior.
} 
Gráfico 1 - Total de cursos na Universidade Federal do Pampa

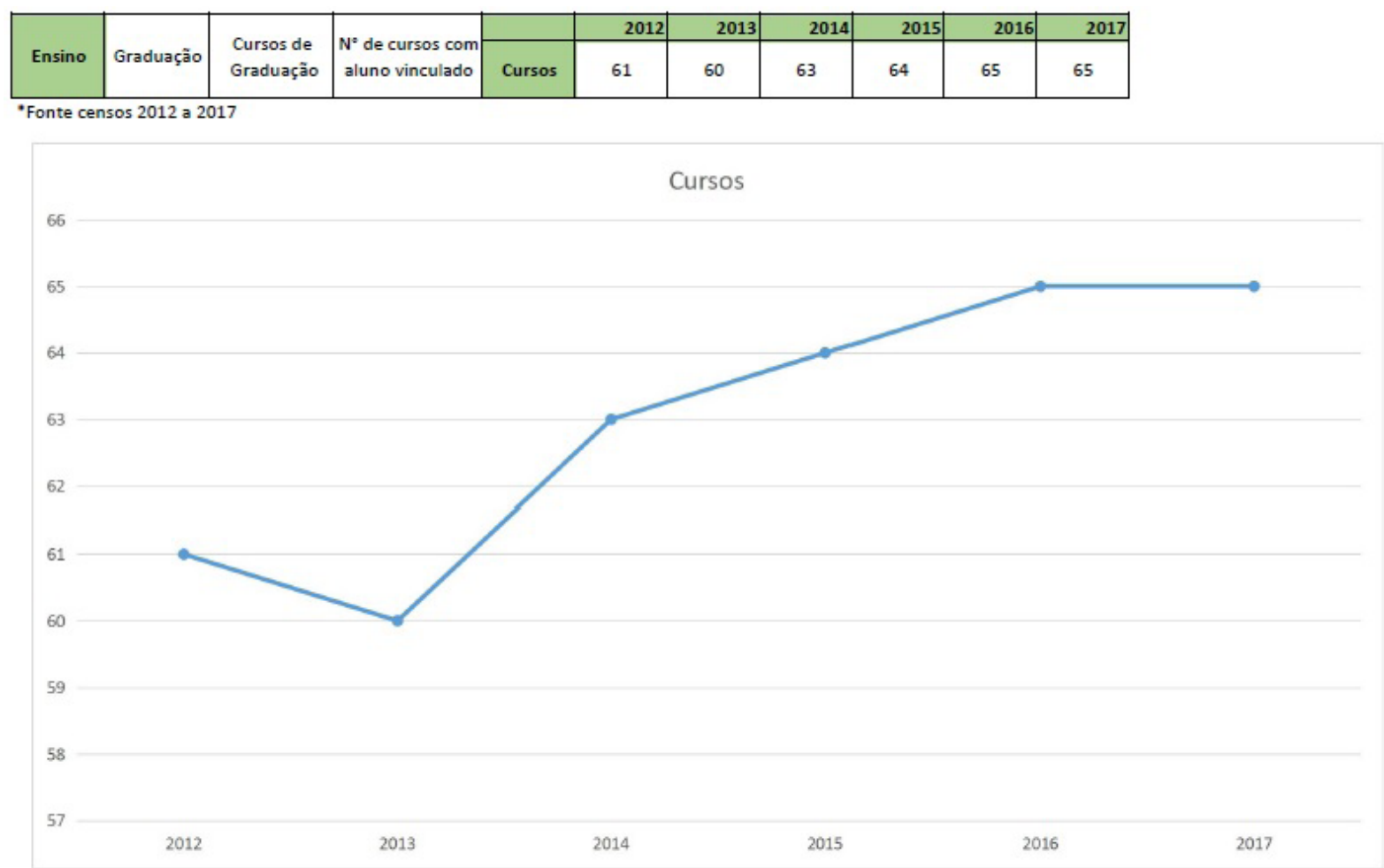

Fonte: https://sites.unipampa.edu.br/proplan/files/2018/08/evolucao-do-n-de-cursos-com-aluno-vinculado.pdf. Acesso em: 16 ago. 2019.

Ao discutir até que ponto começam a alterar o perfil socioeconômico do estudante de graduação brasileiro as políticas como o Prouni, o Programa de Estímulo à Reestruturação e ao Fortalecimento das Instituições de Ensino Superior (Proies), o Programa de Apoio a Planos de Reestruturação das Universidades Federais (Reuni), o Sistema de Seleção Unificada (Sisu), o novo Fundo de Financiamento ao Estudante do Ensino Superior (Fies), a Lei das Cotas nas Instituições Federais, o Plano Nacional de Assistência Estudantil (Pnaes), a criação de novas universidades e novos campi das universidades federais, a interiorização e a criação dos Institutos Federais de Educação, Ristoff (2014) constata que:

Fica, assim, evidente que as políticas adotadas, embora lentas demais na sua execução aos olhos dos que delas precisam e dos indignados pela exclusão histórica, apontam para a direção correta: a educação superior brasileira está criando importantes oportunidades de mobilidade social para alunos trabalhadores, de baixa renda, pretos, pardos, indígenas e filhos de pai sem escolaridade, ampliando significativamente as energias criativas da nação. (RISTOFF, 2014, p. 745-6).

Apesar dos ganhos advindos da ampliação de Universidades públicas e cursos públicos e gratuitos, é importante referir suas contradições e desafios, pois foram gestados em condições muito precárias, com pessoal docente enxuto e com ausência ou incipiência de quadro técnicoadministrativo. Os espaços foram sendo conquistados aos poucos, assim como a inserção de recursos humanos para gerir e ministrar aulas para um grupo de estudantes que chegava a um número de cinquenta ou mais alunos por turma. Nisso, é importante referir que, como protagonistas desse processo, muitas vezes testemunhamos e participamos da multiplicidade de tarefas, hipersolicitação de demandas, desvios de funções, incansáveis reuniões e deslocamentos de uma cidade a outra, 
pelo fato de a Unipampa ser multicampi, a fim de ser possível dar conta das demandas e das dificuldades que se apresentavam. Portanto vale referir que não apenas protagonizamos a criação do curso de Serviço Social em uma universidade pública, mas também participamos na criação dessa universidade pública federal e gratuita, multicampi, no interior do Rio Grande do Sul.

Hoje, em 2019, o curso de Serviço Social da Unipampa já ultrapassou o número de trezentos assistentes sociais egressos(as), oriundos das mais diversas regiões do país, o que permite um intercâmbio cultural impensado antes da criação da Unipampa. Importa realçar que a maioria dos(as) alunos(as) são nativos da fronteira oeste do estado ou das regiões das missões e todo o pampa gaúcho, de forma que é oportunizado o acesso à graduação e viabilizado o acesso à pós-graduação, mesmo que em outras regiões do estado. Antes, quando permitido, havia apenas o acesso ao ensino fundamental e médio; agora, egressos/as do curso estão retornando com doutorados concluídos para assumirem a docência no ensino superior, com acesso ao mercado de trabalho, especialmente servindo de base motivadora para jovens e interessados na qualificação profissional.

A UFSM é a primeira unidade de ensino superior interiorana do Rio Grande do Sul, tendo sido criada pela Lei n. 3.834-C de, 14 de dezembro de 1960. Contudo implantou o curso de Serviço Social (SS) somente em 2010/2, no turno noturno. Esse teve origem por meio do Programa de Apoio a Planos de Reestruturação e Expansão das Universidades Federais, Decreto 6.096, de 2007.

Na sequência, o Gráfico 2 mostra o total de cursos na Universidade Federal de Santa Maria por nível de ensino. Nele, é possível observar que a UFSM oferta 130 cursos de graduação, 106 cursos de pós-graduação (distribuídos em especializações, mestrados e doutorados), nas diferentes áreas do saber da Universidade, e, além disso, tem cinco de ensino médio e 24 de nível pós-médio.

Gráfico 2 - Total de Cursos na Universidade Federal de Santa Maria por nível de ensino

\section{CURSOS POR NIVEL DE ENSINO}

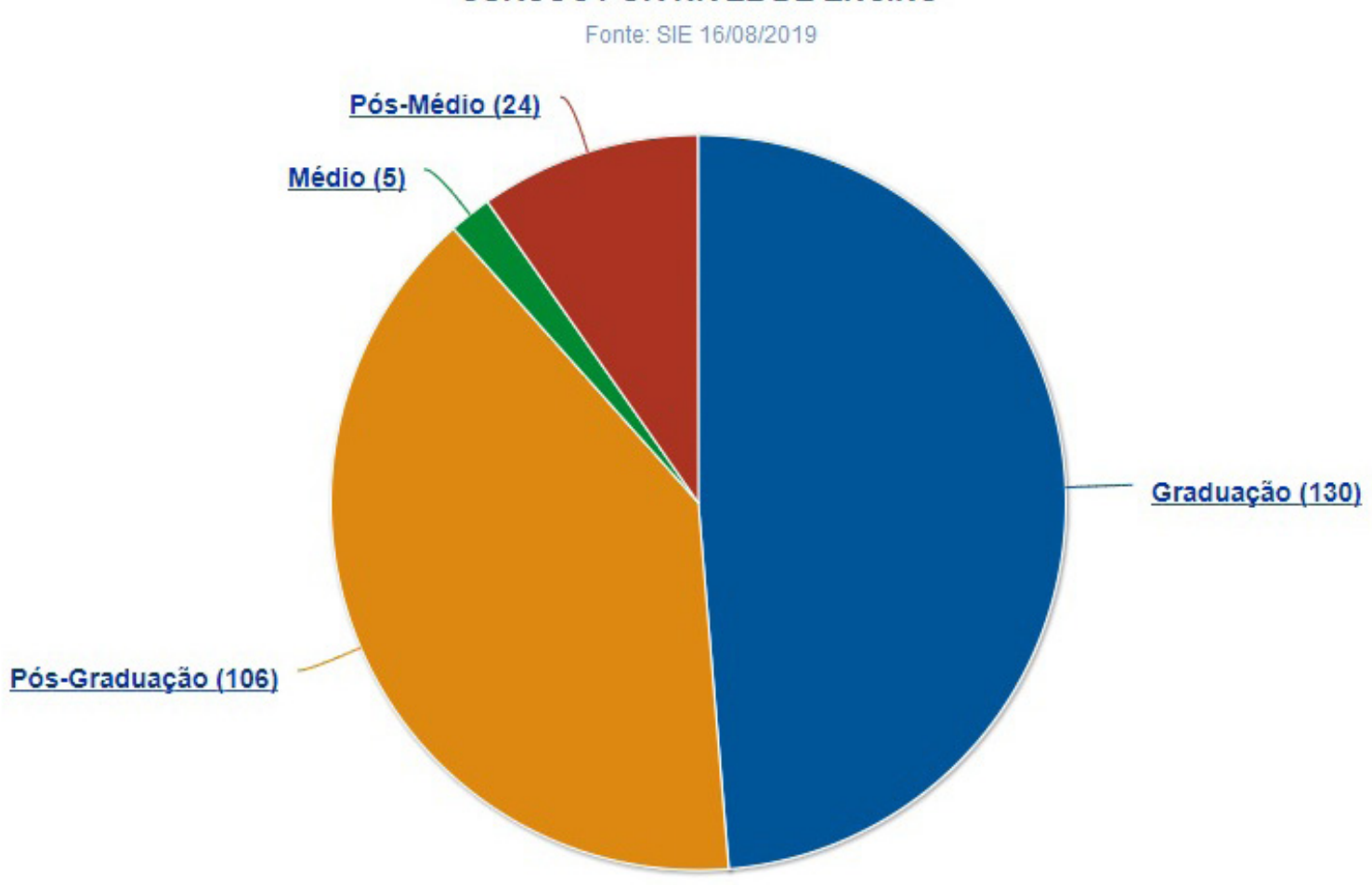

Fonte: https://portal.ufsm.br/ufsm-em-numeros/publico/painel.html;jsessionid=bc4db9f57acc81d1caed2e20664 3?categoria=102. Acesso em: 16 ago. 2019. 
É relevante pontuar que o curso de Serviço Social da UFSM é um dos três cursos de Serviço Social existentes em Instituições Federais de Ensino Superior no Rio Grande do Sul, sendo os outros na Unipampa, já mencionada, e na Universidade Federal do Rio Grande do Sul (UFRGS). A fundação dos cursos de Serviço Social na UFSM e na UFRGS é resultante do Reuni de suas respectivas unidades de ensino e, por isso, muito recente, diferentemente dos cursos de Serviço Social em instituições privadas, como o da Pontifícia Universidade Católica, o mais antigo do estado, inaugurado em 1945. O Reuni é uma das políticas públicas que possibilitaram a criação de mais vagas em cursos já existentes.

A execução de projetos de ensino, pesquisa e extensão comunitária coordenados pelos docentes da área com a participação de acadêmicos do Serviço Social é um dos pilares do ensino de graduação em Serviço Social da UFSM, desde a sua implantação. Exemplo disso são as intervenções que esse curso já vem disponibilizando à comunidade externa à UFSM, por meio dos projetos que são realizados em parceria com a pró-reitoria de extensão e outros setores da UFSM, como na incubadora social de empreendimentos de Economia Popular e Solidária.

Cabe citar, ao revelar a importância do curso no que tange a ações de extensão, que:

A extensão universitária é o processo educativo, cultural e científico que articula o Ensino e a Pesquisa de forma indissociável e viabiliza a relação transformadora entre Universidade e Sociedade. A Extensão é uma via de mão-dupla, com trânsito assegurado à comunidade acadêmica, que encontrará, na sociedade, a oportunidade de elaboração da práxis de um conhecimento acadêmico. No retorno à Universidade, docentes e discentes trarão um aprendizado que, submetido à reflexão teórica, será acrescido àquele conhecimento. Esse fluxo, que estabelece a troca de saberes sistematizados, acadêmico e popular, terá como consequências a produção do conhecimento resultante do confronto com a realidade brasileira e regional, a democratização do conhecimento acadêmico e a participação efetiva da comunidade na atuação da Universidade. Além de instrumentalizadora deste processo dialético de teoria/prática, a Extensão é um trabalho interdisciplinar que favorece a visão integrada do social. (FORPROEX, 1987, s/p).

Ressalta-se que o curso de Serviço Social, por estar formando profissionais críticos e propositivos, tem oportunizado vivências, por meio dos núcleos de ensino, pesquisa e extensão, nos espaços em que os acadêmicos futuramente vão intervir como profissionais da área. Essa realidade faz com que eles possam vivenciar a comunidade local, além de observar e intervir nas várias refrações da questão social, adquirindo conhecimento científico; mas, especialmente, por meio do conhecimento popular, da educação popular, buscam conhecimentos e retroalimentam a universidade e suas pesquisas.

Com quase 60 anos de existência, atuando em atividades de ensino, pesquisa e extensão com excelência, a UFSM, com a criação do curso de Serviço Social, ampliou também as possibilidades e ações de pesquisa que têm permitido "conhecer os problemas do mundo", especialmente relacionadas à questão social e suas refrações, desenvolvendo pesquisas sobre trabalho, refúgio, migrações forçadas e proteção social, violência e formação em serviço social, gênero, família, infância e adolescentes em situação de vulnerabilidade social, mídia e questão social, planejamento e inovação social, políticas públicas, saúde coletiva, gerontologia, entre outras temáticas.

A criação do Departamento de Serviço Social, em 2013, por sua vez, vem possibilitando uma ampliação na assessoria ao trabalho docente e em suas atividades de extensão, ampliando, consequentemente, a eficiência desses projetos. Em 2014, o curso foi avaliado pelo MEC por meio do modelo aplicado pelo Instituto Nacional de Estudos e Pesquisas Educacionais (Inep). Nessa 
avaliação, o curso obteve a nota máxima, equivalente a 5. Desde então, o curso de graduação em Serviço Social se propõe a inserir no mercado de trabalho um perfil de egresंso crítico, propositivo e de elevada qualidade, seguindo as dimensões ético-políticas, teórico-metodológicas e técnicooperativas orientadas pelas Diretrizes Curriculares da Abepss.

O perfil dos estudantes é constituído por estudantes-trabalhadores, na sua maioria do gênero feminino, oriundos de Santa Maria ou de cidades das adjacências dessa. Muitos desses são acadêmicos que pararam de estudar após o ensino médio e conseguiram retornar e cursar a graduação com a possibilidade de oferta do ensino superior público, gratuito e noturno. Conforme constatado em pesquisa de Fraga, Oliveira e Sebastiany (2018, p. 231-2):

[...] é possível afirmar que se trata de um curso constituído por: mulher; acima de 22 anos; heterossexual; solteira; gaúcha; residente em Santa Maria; optou pelo curso por afinidade; usuária do transporte público para se deslocar para as aulas na universidade, levando de 30 minutos à 1 hora tanto para chegar à Ufsm quanto para retornar para casa, obtendo uma média de gasto mensal de $\mathrm{R} \$ 61,00$ à $\mathrm{R} \$ 100,00$; sem filhas (os); dedica aproximadamente para estudos extraclasse por semana de 2 à 4 horas; trabalha de forma remunerada, com cobertura dos direitos trabalhistas, considerando a renda obtida como fundamental para sua sobrevivência; dedica em média de 6 à 8 horas para atividades ou trabalhos que exerce; possui renda familiar de até 02 salários mínimos; autodeclara-se de raça/cor branca; é religiosa praticante; com visão político-ideológica de esquerda; sem relação direta com partido político-partidário; não militante de movimento e/ ou organização social; não participa de núcleos de ensino, pesquisa e extensão na universidade.

Portanto são estudantes heterogêneos em termos de idade, tendo em vista que o curso é composto não somente de jovens, como também de jovens adultos e, ainda, de pessoas que já alcançaram a maturidade. Tal perfil também remete a atenção diferenciada por parte da Coordenação de Curso, da sua respectiva secretaria e do seu corpo docente, por demandarem um atendimento diferenciado de atenção para continuarem seguindo o curso com qualidade, enfrentando a evasão. Sobre essa questão, o mesmo estudo de Fraga, Oliveira e Sebastiany (2018) sinaliza a baixa evasão do curso de Serviço Social da UFSM, enfatizando ser um dos pontos fortes do curso dessa universidade.

Além disso, durante esse curto período de existência, o curso de Serviço Social da UFSM já formou 161 assistentes sociais, sendo que vários desses já conseguiram inserção no mercado de trabalho e outros ingressaram em cursos de pós-graduação, tais como na residência profissional, em mestrados e até em doutorado, o que evidencia a relevância desse curso na formação profissional em Serviço Social no interior do estado do Rio Grande do Sul.

Segundo Garcia e Fernandes (2018), o processo de expansão da graduação e da pósgraduação da área de Serviço Social acompanha uma tendência geral observada a partir da direção adotada pela política de educação no país naquele momento:

Ou seja, não se trata de realidades isoladas. Há uma política nacional e diretrizes internacionais direcionando o modus operandi da educação no Brasil, evidenciada, principalmente, pela via mercantilizada do ensino superior e pela necessidade "imperiosa" de expandir rapidamente esse ensino, sob a égide de um discurso da democratização do acesso, sem haver, entretanto, a devida correspondência das condições necessárias para a permanência na educação superior. (GARCIA; FERNANDES, 2018, p. 272).

No momento atual, contudo, observa-se que essa expansão enfatizada pelas autoras foi estagnada. Mesmo sem as devidas condições para a permanência no ensino superior, é inegável 
que a expansão abriu possibilidades importantes para as classes trabalhadoras e seus(suas) filhos(as); exemplo disso foi a expansão dos cursos de Serviço Social EM Universidades públicas e gratuitas, tais como o curso de Serviço Social da Unipampa e o Curso de Serviço Social da UFSM.

\section{CONSIDERAÇÕES FINAIS}

Os oitenta anos de Serviço Social brasileiro nos remetem a uma consolidação profissional, portanto, um amadurecimento consciente dos desafios e das perspectivas a serem enfrentados e conquistados cotidianamente. Os desafios também nos lançam a perspectiva profissional pautada em desbravar caminhos e superar dificuldades nos diferentes espaços sócio-ocupacionais.

As possibilidades estão sendo visualizadas na expansão do ensino superior na metade sul do Rio Grande do Sul e, mais especificamente, com a criação do primeiro curso de Serviço Social na Unipampa e, posteriormente, na UFRGS e na UFSM, que vem garantindo o ensino superior público, gratuito, no interior do Estado, possibilitando, assim, uma maior capilaridade dos profissionais formados, bem como a ampliação da inserção desses, e ainda alargando os espaços de produção de conhecimento.

Nesta discussão, foi enfatizado que a presença de Universidades em regiões interioranas é um fator importante para o desenvolvimento econômico e social, tendo em vista que elas despertam as vocações/potencialidades da comunidade local. Os municípios com sede de Universidades têm o privilégio de desfrutar de um rico processo de transformação política e cultural, por meio do tripé ensino, pesquisa e extensão. Neste diapasão, o Serviço Social pode contribuir significativamente, na medida em que propõe uma formação crítica e reflexiva, ampliando as possibilidades do fortalecimento da autonomia, cidadania e justiça social dos sujeitos, sejam eles acadêmicos, sejam eles da comunidade em geral.

\section{REFERÊNCIAS}

AGUIAR, Antônio Geraldo de. Serviço Social e Filosofia: das origens a Araxá. São Paulo: Cortez: UNIMEP, 1982.

ASSOCIAÇÃO BRASILEIRA DE ENSINO E PESQUISA E SERVIÇO SOCIAL (ABEPSS). Proposta Básica para o Projeto de Formação Profissional. 1996. Disponível em: http://www.abepss.org.br/ arquivos/textos/documento_201603311138166377210.pdf. Acesso em: 6 jul. 2020.

BRASIL. Lei n. 9.394, de 20 de dezembro de 1996. Estabelece as diretrizes e bases da educação nacional. Brasília, 1996. Disponível em: http://www.planalto.gov.br/ccivil_03/leis/l9394.htm. Acesso em: 6 jul. 2020.

BULLA, Leonia Capaverde. Origens e profissionalização do Serviço Social no Brasil. In: FLINCKINGER, Hans-Georg (Org.). Entre caridade, solidariedade e cidadania: história comparativa do Serviço Social Brasil/Alemanha. Porto Alegre: Edipucrs, 2000.

CHAUÍ. Marilena. A universidade pública sob nova perspectiva. Revista Brasileira de Educação, Rio de Janeiro, n. 24, p. 5-15, set./dez. 2003. Disponível em: https://www.scielo.br/scielo. php?pid=S1413-24782003000300002\&script=sci_abstract\&tlng=pt. Acesso em: 6 jul. 2020. 
CONSELHO FEDERAL DE SERVIÇO SOCIAL (CFESS). Código de Ética Profissional. Resolução CFESS n. 273/93, de 13 de março de 1993. Institui o Código de Ética Profissional dos Assistentes Sociais e dá outras providências. Brasília, março 1993.

DALLA NORA, Helenice Aparecida D. A gênese do Serviço Social no Brasil: trajetória histórica da formação profissional. Revista Temas Sociais em Expressão, Frederico Westphalen, RS, v. 1, n. 1, p. 45-55, 2002.

ENCONTRO DE PRÓ-REITORES DE EXTENSÃO DAS UNIVERSIDADES PÚBLICAS BRASILEIRAS (FORPROEX). Conceito de extensão, institucionalização e financiamento. Brasília, 1987. Disponível em: https://www2.unifap.br/dex/files/2015/04/1987-I-Encontro-Nacional-do-FORPROEX.pdf. Acesso em: 12 jun. 2016.

FALEIROS, Vicente de Paula. Reconceituação no Brasil: uma questão em movimento? São Paulo: Cortez, 2004.

FALEIROS, Vicente de Paula. Estratégias em Serviço Social. São Paulo: Cortez, 1997.

FRAGA, Cristina Kologeski; OLIVEIRA, Ana Flávia Roatt de; SEBASTIANY, Mariana Marques. Perfil socioeconômico das/os estudantes de Serviço Social da Universidade Federal de Santa Maria. Revista Sociais \& Humanas, Santa Maria, RS, v. 31, n. 2, p. 214-36, 2018. Disponível em: https:// periodicos.ufsm.br/sociaisehumanas/article/view/31480/pdf. Acesso em: 30 maio de 2019.

FRANTZ, Walter. Reflexões sobre universidade. In: ANDRADE, Elisabete; ANDRIOLI, Liria Ângela; FRANTZ, Walter (Org.). Educação no contexto da globalização: reflexões a partir de diferentes olhares. Ijuí, RS: Ed. Unijuí, 2013.

FRANTZ, Walter. Desafios à Universidade no espaço das práticas sociais. In: BARCELOS, Eronita Silva; RASIA, Pedro Carlos; SILVA, Enio Waldir da (Org.). Economia solidária: sistematizando experiências. ljuí, RS: Editora Unijuí, 2010.

GARCIA, Maria Lúcia T.; FERNANDEZ, Cristiane B. Graduação e pós-graduação em serviço social no Brasil. Textos \& Contextos, Porto Alegre, v. 17, n. 2, p. 262-75, ago./dez. 2018. Disponível em: http://revistaseletronicas. pucrs.br/ojs/index.php/fass/article/view/30253/17730. Acesso em: 4 ago. 2019.

IAMAMOTO, Marilda Villela. O Serviço Social na contemporaneidade: trabalho e formação profissional. 22. ed. São Paulo: Cortez, 2014a.

IAMAMOTO, Marilda Villela. A formação acadêmico-profissional no serviço social brasileiro. Revista Serviço Social \& Sociedade, São Paulo, n. 120, p. 608-39, out./dez. 2014b. Disponível em: http://dx.doi.org/10.1590/0101-6628.001. Acesso em: 10 ago. 2019.

NETTO, José Paulo. Reconceituação do Serviço Social: 40 anos. Revista Serviço Social \& Sociedade, São Paulo, n. 84, ano XXVI, nov. 2005.

RISTOFF, Dilvo. O novo perfil do campus brasileiro: uma análise do perfil socioeconômico do estudante de graduação. Revista Avaliação (Campinas), Sorocaba, SP, v. 19, n. 3, p. 723-47, nov. 2014. 
VILLAR, Véra Lúcia Carvalho. Formação em Serviço Social: a implantação do curso em universidades públicas federais do Rio Grande do Sul. 2015. 230. f. Tese (Doutorado em Serviço Social)- Faculdade de Serviço Social, Pontifícia Universidade Católica do Rio Grande do Sul (PUCRS), Porto Alegre, 2015.

\section{Sobre os autores:}

Cristina Kologeski Fraga: Pós-doutoranda de Serviço Social pela Faculdade de Psicologia e Ciências da Educação (FPCE) da Universidade de Coimbra, Portugal. Professora associada do Curso de Serviço Social da Universidade Federal de Santa Maria, líder do Núcleo de Estudos, Pesquisa e Extensão em Violência e Serviço Social (Nepevis).E-mail: ckfraga@gmail.com, Orcid: http://orcid.org/0000-0002-9856-2700

Fábio Jardel Gaviraghi: Pós-doutorando em Serviço Social pela Universidade de Coimbra, Portugal. Doutor em Educação nas Ciências pela Universidade Regional do Noroeste do Estado do Rio Grande do Sul (Unijuí). Mestre em Serviço Social pela Pontifícia Universidade Católica do Rio Grande do Sul (PUCRS). Graduado em Serviço Social pela Unijuí. Docente, com dedicação exclusiva, no Departamento de Serviço Social na Universidade Federal de Santa Maria (UFSM). Tem experiência na área de Serviço Social com ênfase nas seguintes áreas: Trabalho, Questão Social, Educação, Incubadoras Sociais, Refugiados e Políticas Sociais. Líder do Núcleo de Estudos, Pesquisa e Extensão em Políticas Sociais, Trabalho e Questão Social (NEPEPSTQS). E-mail: gaviraghiufsm@gmail.com, Orcid: http://orcid.org/0000-0002-6860-6274

Cristina Pinto Albuquerque: Assistente Social. Professora auxiliar da Faculdade de Psicologia e de Ciências da Educação, investigadora integrada do Centro de Estudos Interdisciplinares do Século XX (CEIS20), professora orientadora de Pós-Doutoramento e vice-reitora da Universidade de Coimbra. E-mail: crisalbuquerque@fpce.uc.pt, Orcid: http://orcid.org/0000-0003-4194-8554

Clara Cruz Santos: Assistente Social. Professora de Serviço Social, coordenadora do Mestrado em Intervenção Social, Inovação e Empreendedorismo, membra associada do Observatório de Intervenção Social e Cidadania e professora orientadora de Pós-Doutoramento. E-mail: clarasantos@fpce.uc.pt, Orcid: http://orcid.org/0000-0001-7971-410X 
